\title{
Cloning and Sequence Analysis of the 4-Hydroxybenzoate 3-Hydroxylase Gene from a Cyclohexanecarboxylate-degrading Gram-positive Bacterium, "Corynebacterium cyclohexanicum" Strain ATCC 51369
}

\author{
HiroAKI IWAKI ${ }^{1}$, Hiroshi SAJI ${ }^{1}$, KAZUYA ABE ${ }^{1}$ and Yoshie HASEGAWA ${ }^{1 *}$ \\ ${ }^{1}$ Department of Biotechnology, Faculty of Engineering, Kansai University, Suita, Osaka 564-8680, Japan
}

(Received April 7, 2005-Accepted May 16, 2005)

A DNA fragment that carries the gene encoding 4-hydroxybenzoate 3-hydroxylase (pobA) together with genes encoding a potential regulator (pobR) and a potential transporter (pobK) was cloned from "Corynebacterium cyclohexanicum" strain ATCC 51369, which is herein reclassified as belonging to the genus Arthrobacter. Nucleotide sequencing revealed that the deduced amino acid sequence encoded by the Arthrobacter pobA gene exhibits $42.0-46.7 \%$ identity with that of gram-negative bacteria. The gene organization of the pob cluster differs from that of gram-negative bacteria. The pobA gene product (PobA), expressed in Escherichia coli, preferred NADH over NADPH similar to 4-hydroxybenzoate 3-hydroxylase of ATCC 51369. The Arthrobacter pobA gene was inactivated by insertion of pK19mob. The resultant mutant strain, POBA1, grew on neither cyclohexanecarboxylate nor 4-hydroxybenzoate. These results strongly suggest that the cloned pobA gene plays an essential role in the catabolism not only of 4-hydroxybenzoate but also of cyclohexanecarboxylate in strain ATCC 51369.

Key words: cyclohexanecarboxylate, biodegradation, 4-hydroxybenzoate 3-hydroxylase, Arthrobacter, "Corynebacterium cyclohexanicum"

Alicyclic acids such as cyclohexanecarboxylate (CHCA) and cyclohexylacetate are formed oxidatively from $n$-alkylcycloparaffins present in crude oils ${ }^{34)}$, and CHCA is also involved as an intermediate in the anaerobic degradation of aromatic rings ${ }^{8,9,36)}$.

The utilization of CHCA as a source of carbon for growth by a number of aerobic bacteria appears to follow two main routes: aromatization of the ring to yield hydroxybenzoate as an intermediate, which is a substrate for ring opening $^{3,17,19)}$, or metabolization by a $\beta$-oxidation-like sequence, involving coenzyme A thioester-derivatives, before ring opening 2,25$)$. "Corynebacterium cyclohexanicum" strain ATCC 51369 degrades CHCA through a pathway that includes aromatization (Fig. 1) ${ }^{19,20,33)}$. The degradation of CHCA has been found to be initiated by hydroxylation to yield 4-hydroxyCHCA, which is then dehydrogenated to 4-

\footnotetext{
* Corresponding author; E-mail: yoshie@ipcku.kansai-u.ac.jp, Tel: +81-6-6368-0909, Fax: +81-6-6388-8609
}

oxoCHCA by a $\mathrm{NAD}^{+}$-dependent dehydrogenase ${ }^{23)}$. The next step, catalyzed by the third and fourth enzymes in the degradation pathway, which are two distinctive desaturases, is the aromatization of 4-oxoCHCA to 4-hydroxybenzoate $(4-\mathrm{HBA})^{19,20)}$. 4-HBA is then converted to protocatechuate, a common intermediate in the biodegradation of various aromatic compounds, by 4-HBA 3-hydroxylase (PHBH) which utilizes NADH as well as NADPH as an electron donor $^{16)}$.

We have initiated a genetic analysis of strain ATCC 51369 to further characterize the pathway of CHCA's degradation and report here for the first time the cloning and sequencing of a gene cluster that contains the $\mathrm{PHBH}$ gene (pobA) of gram-positive bacteria.

\section{Materials and Methods}

\section{Bacterial strains, culture conditions, and plasmids}

The bacterial strains and plasmids used in this study are 


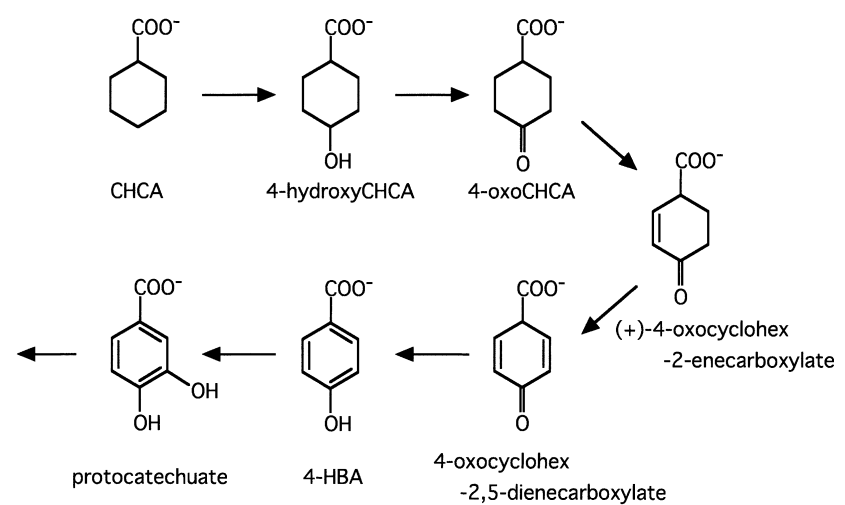

Fig. 1. Pathway for the degradation of cyclohexanecarboxylate (CHCA) by Arthrobacter sp. strain ATCC 51369. PobA, 4-hydroxybenzoate (4-HBA) 3-hydroxylase which converts 4-HBA to protocatechuate.

listed in Table 1. "Corynebacterium cyclohexanicum" strain ATCC 51369, reclassified as a member of the genus Arthrobacter, was grown at $30^{\circ} \mathrm{C}$ in Luria-Bertani (LB) medium ${ }^{26}$ or mineral salt medium (MSM) ${ }^{18)}$, $\mathrm{pH} 7.0$, containing $0.1 \%$ CHCA, 4-HBA, or protocatechuate and $0.1 \mathrm{~g}$ of yeast extract per liter. Agar was added to $1.5 \%$ for plates. Escherichia coli strains were routinely cultured in LB media. When necessary, the media were supplemented with ampicillin $(100 \mu \mathrm{g} / \mathrm{ml})$ or kanamycin $(100 \mu \mathrm{g} / \mathrm{ml})$.

\section{Genetic methods and sequence analysis}

All of the DNA techniques used, including isolation of total DNA from strain ATCC 51369, plasmid isolation, Southern blot analysis, DNA labeling, DNA subcloning, nucleotide sequencing, electrotransformation (electroporation), and 16S rRNA gene analysis, were performed as described previously ${ }^{6,18,22)}$.

\section{Cloning of the PHBH-encoding gene (pobA) and associated open reading frames (ORFS)}

To clone the pobA involved in the degradation of CHCA, we purified the $\mathrm{PHBH}$ protein from $\mathrm{CHCA}$-grown cells as described previously ${ }^{16)}$, with the aim of determining an Nterminal amino acid sequence to design a primer for PCR amplification. As a result, a 20-amino-acid-residue sequence, GDRTVITTQVAIMGAGPAGL, was obtained by Edman degradation using a Perkin-Elmer model 477 automated protein sequencer. Two primers with the following sequences were designed from the N-terminal amino acid sequence (TTQVAIMG) and a conserved sequence (HIVPPTGA) of PHBH 1,7,10,24,29,30,37): 5'-ACIACICARGTNGCNATHATGGG-3' and 5'-GCICCIGTNGGIGGNACDATRTG-3'. PCR amplifications were carried out in $50 \mu \mathrm{l}$ reaction mixtures containing $0.1 \mu \mathrm{g}$ of strain ATCC 51369 genomic DNA as a template, 50 pmol of each primer, each

Table 1. Bacterial strains and plasmids used in this study

\begin{tabular}{|c|c|c|}
\hline Strain or plasmid & Relevant characteristic $(\mathrm{s})^{\mathrm{a}}$ & Reference or source \\
\hline \multicolumn{3}{|l|}{ Arthrobacter sp. strains } \\
\hline ATCC 51369 & CHCA degrader, $\mathrm{Chc}^{+}, \mathrm{Pob}^{+}, \mathrm{Pca}^{+}$ & 33 \\
\hline POBA1 & pobA mutant of strain ATCC $51369, \mathrm{Chc}^{-}, \mathrm{Pob}^{-}, \mathrm{Pca}^{+}$ & This study \\
\hline \multicolumn{3}{|l|}{ E. coli strains } \\
\hline XL1-blue & recAl endA1 gyrA96 thi hsdR17 supE44 relA1 [F' lacl ${ }^{\mathrm{q}} \mathrm{ZM} 15 \operatorname{Tn} 10\left(\right.$ Tet $\left.\left.^{\mathrm{r}}\right)\right]$ & 4 \\
\hline BL21 & $\mathrm{F}^{-}$ompT hsdS $S_{B}\left(\mathrm{r}_{\mathrm{B}}^{-} \mathrm{m}_{\mathrm{B}}^{-}\right) \mathrm{gal} \mathrm{dcm}$ & Novagen \\
\hline \multicolumn{3}{|l|}{ Plasmids } \\
\hline pUC19 & Cloning vector, $\mathrm{Ap}^{\mathrm{r}}$ & 38 \\
\hline pK19mob & Mobilizable multi-purpose cloning vector, $\mathrm{Km}^{\mathrm{r}}$ & 27 \\
\hline pSD80 & Expression vector with $t a c$ promoter, $\mathrm{Ap}^{\mathrm{r}}$ & 31 \\
\hline pXemkn12 & Direct cloning vector of $\mathrm{PCR}$ products, $\mathrm{Ap}^{\mathrm{r}}, \mathrm{Km}^{\mathrm{r}}$ & 5 \\
\hline $\mathrm{pXcm}-p o b A$ & $\begin{array}{l}\text { 0.9-kb PCR product containing the partial pobA gene from Arthrobacter sp. strain } \\
\text { ATCC } 51369 \text { genomic DNA in pXcmkn12 }\end{array}$ & This study \\
\hline pHBA1 & 7.3-kb PstI fragment from Arthrobacter sp. strain ATCC 51369 in pUC19 & This study \\
\hline pPobA & 1.2-kb EcoRI*-PstI* fragment containing pobA in pSD80 & This study \\
\hline pK19-pobA & 0.6-kb BglII fragment containing the internal region of $p o b A$ in $\mathrm{pK} 19 m o b$ & This study \\
\hline
\end{tabular}

${ }^{\mathrm{a}} \mathrm{Chc}^{+}$, growth on CHCA; $\mathrm{Chc}^{-}$, no growth on $\mathrm{CHCA} ; \mathrm{Pob}^{+}$, growth on 4-HBA; $\mathrm{Pob}^{-}$, no growth on 4-HBA; $\mathrm{Pca}^{+}$, growth on protocatechuate. $*$ indicates restriction sites introduced by design. 
dNTP at a concentration of $0.2 \mathrm{mM}, 5 \mu \mathrm{l}$ of Taq DNA buffer, and 2.5 units of Taq DNA polymerase (New England Biolabs, Beverly, USA). After 3 min of incubation at $94^{\circ} \mathrm{C}$, the reaction mixture was subjected to 30 cycles of $15 \mathrm{~s}$ at $94^{\circ} \mathrm{C}, 30 \mathrm{~s}$ at $50^{\circ} \mathrm{C}$, and $1 \mathrm{~min}$ at $72^{\circ} \mathrm{C}$. The $0.9-\mathrm{kb}$ PCR

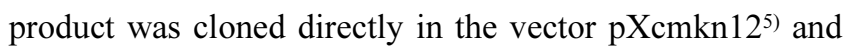
introduced into E. coli XL-1 blue. The resulting plasmid was designated $\mathrm{pXcm}-p o b A$. Before use of the amplified DNA as a hybridization probe, its nucleotide sequence was determined to confirm its identity. To clone the complete $p o b A$ gene, the DNA insert from pXcm-pobA was amplified, labeled with the digoxigenin-11-UTP system (Roche Diagnostics), and used for the Southern hybridization of genomic DNA digested with the following enzymes: BamHI, EcoRI, HindIII, KpnI, PstI, SalI, SphI, and XbaI. A 7.3-kb PstI fragment was cloned in E. coli XL1-blue cells by using pUC19 as a vector ${ }^{38)}$. A clone containing the $7.3-\mathrm{kb}$ insert was screened by colony hybridization using the PCR product as a probe; this recombinant plasmid was designated pHBA1, and both strands of the insert were sequenced.

\section{Expression of the pobA gene in E. coli and enzymatic activity}

The DNA fragment carrying pobA was amplified by using KOD polymerase (Toyobo, Japan, Osaka) with the following pair of PCR primers, with the desired restriction site (EcoRI and PstI [underlined sequence]) to facilitate subsequent cloning: pobAF (5'-CGGAATTCATGGGCGATCGCACCGTCAT-3') and pobAR (5'-AAAACTGCAGCTTCTGGGTGTCATGTC-3').

The amplified DNA fragment was purified from an agarose gel, digested with EcoRI and PstI, and cloned in the linearized pSD80 ${ }^{31)}$ vector to yield pPobA. E. coli BL21 containing pPobA was cultivated in $20 \mathrm{ml}$ of LB medium containing $100 \mu \mathrm{g} / \mathrm{ml}$ ampicillin at $30^{\circ} \mathrm{C}$. When the culture reached an optical density at $600 \mathrm{~nm}$ of 0.5 , IPTG was added to a final concentration of $0.5 \mathrm{mM}$ in the medium. The cells were further cultured for $3 \mathrm{~h}$. The resultant cells were harvested by centrifugation, washed in $50 \mathrm{mM}$ phosphate buffer ( $\mathrm{pH}$ 7.2), resuspended in the same buffer, and sonicated by two 30-s bursts with a Braun-Sonifier 250 apparatus. After centrifugation for $30 \mathrm{~min}$ at $18,000 \times g$ at $4^{\circ} \mathrm{C}$, the supernatant was used for the determination of enzyme activity. $\mathrm{PHBH}$ activities were assayed spectrophotometrically by measuring the decrease in absorbance of $340 \mathrm{~nm}$ due to the substrate-dependent oxidation of NADPH or NADH as described by Fujii and Kaneda ${ }^{16)}$. The standard assay system contained $50 \mu \mathrm{mol}$ phosphate buffer, $\mathrm{pH} 7.7,0.15 \mu \mathrm{mol}$ NADPH or NADH, $0.25 \mu \mathrm{mol} 4-\mathrm{HBA}, 0.025 \mu \mathrm{mol} F A D$, enzyme solution and water. One unit of enzyme activity was defined as the amount catalyzing the oxidation of $1.0 \mu \mathrm{mol}$ $\mathrm{NAD}(\mathrm{P}) \mathrm{H} / \mathrm{min}$ under the conditions of the assay.

\section{Inactivation of pobA in Arthrobacter}

To disrupt the $p o b A$ gene, a $0.6-\mathrm{kb} B g l \mathrm{II}$ fragment containing the internal region of pobA was inserted into the BamHI site of $\mathrm{pK} 19 m o b^{27)}$. The resultant plasmid pK19-po$b A$, was introduced into strain ATCC 51369 by electroporation. A single crossover was expected to generate a tandemly duplicated pobA sequence, resulting in a vector between the sequences. Because the $p o b A$ gene in pK19-pobA was truncated at both termini, the upstream pobA sequence lacked the carboxyl terminus, and the downstream $p o b A$ sequence lacked the amino terminus. As a result, both of the pobA sequences had deletions, and neither of them was functional. Transformants were selected on LB agar plates containing $100 \mu \mathrm{g} / \mathrm{ml}$ kanamycin and were subjected to a PCR amplification analysis using primers pobAF and pobAS in order to examine the insertion of $\mathrm{pK} 19-p o b A$ into the pobA gene by single crossover.

\section{Nucleotide sequence accession number}

The DNA sequences reported in this paper have been submitted to DDBJ, and the accession numbers are AB210281 (7.3-kb PstI fragment), AB210282 (16S rRNA gene).

\section{Results and Discussion}

\section{Reclassification of strain ATCC 51369}

As the proper identification of a genus or strain is a prerequisite in a potential risk assessment scheme, strain ATCC 51369 was subjected to a 16S rRNA gene sequence analysis. As a result, analysis of the near-complete 1,453-bp 16S rRNA gene sequence of strain ATCC 51369 indicated that it belonged to the genus Arthrobacter with Arthrobacter atrocyaneus (DDBJ/EMBL/GenBank accession number, AY605543) as its closest relative (99.0\% similarity). Based on this result, it is proposed that "Corynebacterium cyclohexanicum" strain ATCC 51369 is reclassified as an Arthrobacter sp.

\section{Cloning of PHBH-encoding gene}

As described in Materials and Methods, two primers were designed based on the N-terminal amino acid sequence of the purified protein and a conserved sequence of PHBH $^{1,7,10,24,29,30,37)}$ and used to amplify the partial pobA gene. The amplified product was used as a probe for a 


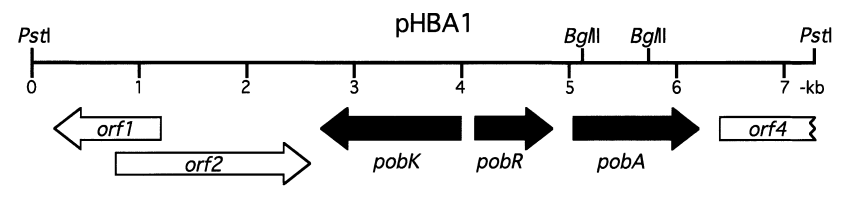

Fig. 2. Physical map of the pob gene cluster from Arthrobacter sp. strain ATCC 51369. The orientation of the arrows indicates the direction of gene transcription. The black arrows are genes involved in the degradation of 4-HBA. pobR is a putative regulatory gene and $p o b K$ encodes a putative transporter. Other ORFs are marked by open arrows.

Southern and colony hybridization, and a 7.3-kb Pst Iragment of strain ATCC 51369 genomic DNA was obtained. The plasmid was designated pHBA1. Using pHBA1 as a template, the insert was sequenced. On the basis of an analysis of the DNA sequence data, we predicted the presence of five complete and one incomplete open reading frames (ORFs) (Fig 2; Table 2). Three are on one strand, and the rest are on the opposite strand.

Based on a comparison of N-terminal amino acid sequence with purified PHBH from strain ATCC 51369, the 1,188-bp ORF preceded by a consensus ribosome-binding sequence, AAGGA, was identified as the PHBH-encoding gene $(p o b A)$. Its first 20 amino acids deduced from the nucleotide sequence were identical to the sequence determined in this study except for the N-terminal methionine. This result suggests that we have cloned the PHBH gene required for degradation of CHCA.

\section{Characteristics of pobA and flanking sequences}

The deduced amino acid sequence of pobA consisted of 396 residues and had a calculated molecular mass of $44 \mathrm{kDa}$. It exhibited $42.0-46.7 \%$ identity with published PobA sequences of gram-negative bacteria and all active site residues in the novel sequence were strictly conserved ${ }^{1,7,10,24,29,30,37)}$. As expected, the most closely related sequence according to the phylogenetic analysis (data not shown) was PHBH from Pseudomoans sp. strain CSB3 which prefers NADH over NADPH, as well as PHBH of ATCC 51369. To the best of our knowledge, PobA from Pseudomonas sp. strain CBS3 was the only PHBH enzyme known to be active with $\mathrm{NADH}^{29}$. The $p o b A$ gene product of strain ATCC 51369 represents the second PHBH that is active toward NADH to be cloned and sequenced, and the first from gram-positive bacteria. The model of coenzyme recognition by flavoprotein aromatic hydroxylases mainly comes from studies on the NADPH-specific PHBH of Pseudomonas fluorescens ${ }^{11-14)}$. The pyrophosphate moiety of NADPH most probably binds in a cleft between the FAD-binding domain and the substrate-binding domain, whereas the adenosine 2'-phosphate moiety is assumed to bind in the region around helix $\mathrm{H}_{2}^{28,35}$ ) and $\mathrm{Tyr} 38$ may play an important role in the recognition of the adenosine 2'phosphate moiety ${ }^{29)}$. The amino acid sequence of the helix

Table 2. Homology of the Arthrobacter sp. strain ATCC 51369 gene products or ORFs

\begin{tabular}{|c|c|c|c|c|}
\hline Gene designation & $\begin{array}{l}\text { Function of } \\
\text { gene product }\end{array}$ & $\begin{array}{l}\text { Position in } \\
\text { sequence }^{\mathrm{a}}\end{array}$ & $\begin{array}{l}\text { Amino } \\
\text { acid (aa) }\end{array}$ & $\begin{array}{l}\text { Most similar gene products [species] (accession no.) } \\
{[\% \text { aa identity (identical aa/overlapped aa) }]^{\mathrm{b}}}\end{array}$ \\
\hline orf1 & Possible transposase & $190-1,200$ & 336 & $\begin{array}{l}\text { Putative transposase [Corynebacterium efficiens YS-314] (BAC18275) } \\
\text { [55.4 (152/285)], Putative transposase [Gloeobacter violaceus PCC } \\
7421] \text { (BAC88274) [53.1 (135/254)] }\end{array}$ \\
\hline orf 2 & Possible transposase & $760-2,571$ & 603 & $\begin{array}{l}\text { Putative transposase [Mycobacterium ulcerans AGY99] (CAE46838) } \\
{[68.0(185 / 272)], \text { Putative transposase [Azoarcus sp. EbN1] (CAI09985) }} \\
{[44.9(183 / 408)]}\end{array}$ \\
\hline pobK & $\begin{array}{l}\text { Possible 4-HBA } \\
\text { transporter }\end{array}$ & $2,672-3,991$ & 439 & $\begin{array}{l}\text { Putative transmembrane transport protein [Streptomyces coelicolor A3 } \\
\text { (2)] (CAB76354) [51.0 (224/439)], Permeases of the major facilitator } \\
\text { superfamily [Corynebacterium glutamicum ATCC 13032] (BAB98469) } \\
\text { [47.7 (195/409)] }\end{array}$ \\
\hline pobR & IclR-type regulator & $4,105-4,851$ & 248 & $\begin{array}{l}\text { Putative transcriptional regulator [Corynebacterium glutamicum R] } \\
\text { (BAD83943) [39.5 (98/248)], Putative transcriptional regulator } \\
\text { [Streptomyces coelicolor A3 (2)] (CAA19948) [37.0 (88/238)] }\end{array}$ \\
\hline$p o b A$ & PHBH & $5,033-6,223$ & 396 & $\begin{array}{l}\text { Putative 4-hydroxybenzoate hydroxylase [Bradyrhizobium japonicum } \\
\text { USDA 110] (BAC51685) [50.8 (197/388)], Putative 4-hydroxybenzoate } \\
\text { 3-monooxygenase [Corynebacterium efficiens YS-314] (BAC17943) } \\
{[49.0(190 / 388)]}\end{array}$ \\
\hline $\operatorname{orf3}\left(5^{\prime}\right.$-truncated $)$ & Possible transposase & $6,379-7,287$ & 303 & $\begin{array}{l}\text { Predicted transposase [Corynebacterium glutamicum ATCC 13032] } \\
\text { (BAC00025) [37.4 (114/305)], Predicted transposase [Corynebacterium } \\
\text { glutamicum ATCC 13032] (BAC00345) [40.8 (91/223)] }\end{array}$ \\
\hline
\end{tabular}

\footnotetext{
${ }^{a}$ The numbers are nucleotide positions in the sequenced segment (DDBJ/EMBL/GenBank accession no. AB210281).

${ }^{\mathrm{b}}$ Nonredundant protein databases in the National Center for Biotechnology Information.
} 
$\mathrm{H} 2$ region is highly conserved in NADPH-specific $\mathrm{PHBH}$ enzymes ${ }^{1,7,10,24,30,37)}$, but deviates in the NAD(P)H-dependent PHBH from strain CBS3 in which Tyr38 is replaced by glutamic acid ${ }^{29}$. Based on this finding, it was proposed that helix $\mathrm{H} 2$ was involved in determining the coenzyme specificity. Actually, Eppink et al. succeeded in switching the coenzyme specificity of $P$. fluorescens $\mathrm{PHBH}$ by introducing multiple substitutions into helix H2 (33-RQTPDYVLGR42) based on the sequence of PHBH from Pseudomonas sp. CBS3 (37-SRSRAEIEST-46) and concluded that specificity in $P$. fluorescens $\mathrm{PHBH}$ is conferred by interactions of Arg33, Tyr38 and Arg42 with the 2'-phosphate moiety of bound NADPH, and that introduction of an acidic group at position 38 potentially enables the recognition of the 2'-hydroxy group of NADH. As expected given these findings, this region is highly conserved in two PHBHs from strains CBS3 (37-SRSRAEIEST-46) and ATCC 51369 (39IRSRAEISAT-48), providing new insight into the mode of coenzyme recognition by $\mathrm{PHBH}$.

Upstream of pobA and separated by a 181-bp intergenic sequence is a potential IclR-type transcriptional regulator ${ }^{32)}$. This ORF, designated pobR, consists of 248 residues with a ribosome-binding sequence (GGA). PobR is most closely related to the putative transcriptional regulator of Corynebacterium glutamicum strain R (Table 2), and the PobR of Acinetobacter is the first regulatory protein for a PHBH-encoding gene to be identified in a BLASTP search, with identities of $39.5 \%$ and $23.7 \%$, respectively. No significant homology was detected with other PobR using the Blast 2 program, which suggests that PobR from this strain and Acinetobacter belong to another family of regulatory proteins. The open reading frames of $p o b R$ and $p o b A$ are oriented in the same direction (Fig. 2). This orientation differs from published $p o b$ gene clusters in gram-negative bacteria, where $p o b A$ and $p o b R$ are oriented in opposing directions.

One hundred and thirteen base pairs upstream of $p o b R$, but transcribed in the reverse orientation and preceded by a consensus ribosome-binding sequence, GAGGT, is a 1,317bp ORF designated $p o b K$ that encodes a polypeptide of 439 residues which is a putative 4-HBA transporter. PobK is most closely related to a putative transmembrane transport protein of Streptomyces coelicolor strain A3 (2) (Table 2), and benzoate transport protein, BenK, is the first functional protein identified by a BLASTP search with 50.4 and $30.7 \%$ identity, respectively ${ }^{21)}$. A PobK homolog was not found in flanking sequences of $p o b A$ and $p o b R$ in gram-negative bacteria. Also, three transposase-like genes are in the flanking region of the pob degradative cluster (Table 2, Fig. 2).

\section{Expression of pobA in E. coli}

A knowledge of the $p o b A$ nucleotide sequence was used to construct a IPTG-inducible clone of $E$. coli cells using the plasmid pSD80 as a vector in order to verify its protein production and enzymatic activity. Figure 3 shows the expression of the PobA protein (lane 2) and the observed $M_{\mathrm{r}}$ estimated at $45 \mathrm{kDa}$. No enhanced protein band of this size was detectable in the control cells containing pSD80 only.

Crude protein extract from the $E$. coli BL21 cells containing pPobA was used to determine the enzymatic activity as described in Materials and Methods. As a result, the specific activity of the PHBH enzyme was found to be 3.7 and 2.3 $\mathrm{U} / \mathrm{mg}$ using NADH and NADPH as an external electron donor, respectively.

\section{Disruption of the pobA gene in strain ATCC 51369}

To examine if the cloned pobA gene is essential to the catabolism of CHCA and 4-HBA in strain ATCC 51369, the pobA gene was insertionally inactivated by homologous recombination. We constructed the plasmid pK19-pobA to inactivate $p o b A$ by single crossover and introduced it into strain ATCC 51369 by electroporation. A kanamycin-resistant transformant, POBA1, was recovered and PCR amplification was performed to confirm the expected arrangement of duplicated $p o b A$ sequences. The amplified fragment from strain POBA1 genomic DNA was 4.4-kb larger than that of ATCC 51369, indicating that insertion of the entire 4.4-kb pK19-pobA segment into the pobA sequence occurred (data

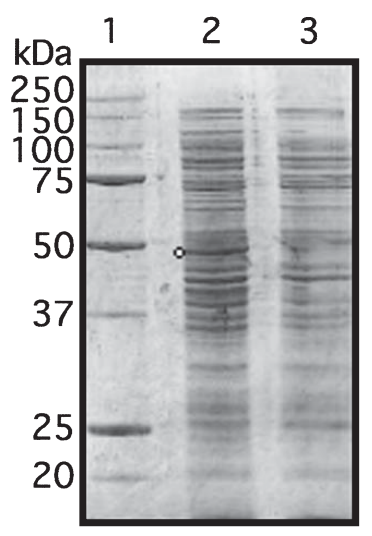

Fig. 3. Coomassie blue-stained protein profile of recombinant $E$. coli crude extracts separated by SDS- $10 \%$ polyacrylamide gel electrophoresis. Lane 1 shows molecular size markers as indicated alongside in kilodaltons; the open circle in lane 2 indicates the positions of the expression of PobA in the clone pPobA (see Table 1). Lane 3 is a control with $E$. coli cells containing the pSD80 vector only. 
not shown). Strain POBA1 did not grow on CHCA and 4HBA. In contrast, when protocatechuate was used as the sole source of carbon, no significant difference was observed between the growth rates of POBA1 and ATCC 51369 (data not shown). This result strongly suggested that the cloned pobA gene was essential for the metabolism of CHCA and 4-HBA.

\section{Acknowledgments}

This research was financially supported in part by a Kansai University Grant-in-aid for the Promotion of Advanced Research in a Graduate Course, 2005 and by a High-Tech Research Center Project for Private Universities: matching fund subsidy from MEXT (Ministry of Education, Culture, Sports, Science and Technology), 2002-2006.

\section{References}

1) Bertani, I., M. Kojic and V. Venturi. 2001. Regulation of the $p$ hydroxybenzoic acid hydroxylase gene (pobA) in plant-growthpromoting Pseudomonas putida WCS358. Microbiol. 147: 16111620.

2) Blakley, E.R. 1978. The microbial degradation of cyclohexane carboxylic acid by $\beta$-oxidation pathway with simultaneous induction to the utilization of benzoate. Can. J. Microbiol. 24: 847854.

3) Blakley, E.R. 1974. The microbial degradation of cyclohexane carboxylic acid: a pathway involving aromatization to form $p$-hydroxybenzoic acid. Can. J. Microbiol. 20: 1297-1306.

4) Bullock, W.O., J.M. Fernandez and J.M. Stuart. 1987. XL-1 Blue: a high efficiency plasmid transforming recA Escherichia coli strain with beta-galactosidase selection. BioTechniques $\mathbf{5}$ : 376-379.

5) Cha, J., W. Bishai and S. Chandrasegaran. 1993. New vectors for direct cloning of PCR products. Gene 136: 369-370.

6) Denis-Larose, C., H. Bergeron, D. Labbé, C.W. Greer, J, Hawari, M.J. Grossman, B.M. Sankey and P.C.K. Lau. 1998. Characterization of the basic replicon of Rhodococcus plasmid pSOX and development of a Rhodococcus-Escherichia coli shuttle vector. Appl. Environ. Microbiol. 64: 4363-4367.

7) DiMarco, A.A., B.A. Averhoff, E.E. Kim and L.N. Ornston. 1993. Evolutionary divergence of $p o b A$, the structural gene encoding $p$-hydroxybenzoate hydroxylase in an Acinetobacter calcoaceticus strain well-suited for genetic analysis. Gene 125: 2533.

8) Dutton, P.L. and W.C. Evans. 1969. The metabolism of aromatic compounds by Rhodopseudomonas palustris. Biochem. J. 113: 525-536.

9) Egland, P.G., D.A. Pelletier, M. Disoensa, J. Gibson and C.S. Harwood. 1997. A cluster of bacterial genes for anaerobic benzene ring biodegradation. Proc. Natl. Acad. Sci. USA. 94: 64846489 .

10) Entsch, B., Y. Nan, K. Weaich and K.F. Scott. 1988. Sequence and organization of $p o b A$, the gene coding for $p$-hydroxybenzoate hydroxylase, an inducible enzyme from Pseudomonas aeruginosa. Gene 71: 279-291.

11) Eppink, M.H.M., H.A. Schreuder, and W.J.H. van Berkel. 1995. Structure and function of mutant Arg44Lys of $p$-hydroxybenzoate hydroxylase. Eur. J. Biochem. 231: 157-165.

12) Eppink, M.H.M., H.A. Schreuder, and W.J.H. van Berkel. 1998. Lys42 and Ser42 variants of $p$-hydroxybenzoate hydroxylase from Pseudomonas fluorescens reveal that Arg42 is essential for NADPH binding. Eur. J. Biochem. 253: 194-201.

13) Eppink, M.H.M., H.A. Schreuder, and W.J.H. van Berkel. 1998. Interdomain binding of NADPH in $p$-hydroxybenzoate hydroxylase as suggested by kinetic, crystallographic and modeling studies of His162 and Arg269 variants. J. Biol. Chem. 273: 2103121039.

14) Eppink, M.H.M., H.A. Schreuder, and W.J.H. van Berkel. 1999. Phe161 and Arg166 variants of $p$-hydroxybenzoate hydroxylase. Implications for NADPH recognition and structural stability. FEBS Letters. 443: 251-255.

15) Eppink, M.H.M., K.M. Overkamp, H.A. Schreuder, and W.J.H. van Berkel. 1999. Switch of coenzyme specificity of $p$-hydroxybenzoate hydroxylase. J. Mol. Biol. 292: 87-96.

16) Fujii, T. and T. Kaneda. 1985. Purification and properties of NADH/NADPH-dependent $p$-hydroxybenzoate hydroxylase from Corynebacterium cyclohexanicum. Eur. J. Biochem. 147: 97-104.

17) Hasegawa, Y., K. Higuchi, H. Obata F. Yoshizako, A. Nishimura, M. Chubachi and T. Tokuyama. 1987. Metabolism of cyclohecxanecarboxylic acid by Trichosporon cutanium KUY-6A. Nippon Nogeikagaku Kaishi (in Japanese), 61: 1107-1112.

18) Iwaki, H., Y. Hasegawa, S. Wang, M.M. Kayser and P.C.K. Lau. 2002. Cloning and characterization of a gene cluster involved in cyclopentanol metabolism in Comamonas sp. strain NCIMB 9872 and biotransformations effected by Escherichia coli-expressed cyclopentanone 1,2-monooxygenase. Appl. Environ. Microbiol. 68: 5671-5684.

19) Kaneda, T. 1974. Enzymatic aromatization of 4-ketocyclohexanecarboxylic acid to $p$-hydroxybenzoic acid. Biochem. Biophys. Res. Comm. 58: 140-144.

20) Kaneda, T., H. Obata and T. Tokuyama. 1993. Aromatization of 4-oxocyclohexanecarboxylic acid to 4-hydroxybenzoic acid by two distinctive desaturases from Corynebacterium cyclohexanicum properties of two desaturases. Eur. J. Biochem. 218: 9971003 .

21) Kitagawa, W., K. Miyauchi, E. Masai and M. Fukuda. 2001. Cloning and characterization of benzoate catabolic genes in the gram-positive polychlorinated biphenyl degrader Rhodococcus sp. strain RHA1. J. Bacteriol. 183: 6598-6606.

22) Muraki, T., M. Taki, Y. Hasegawa, H. Iwaki and P.C.K. Lau. 2003. Prokaryotic homologs of the eukaryotic 3-hydroxyanthranilate 3,4-dioxygenase and 2-amino-3-carboxymuconate-6-semialdehyde decarboxylase in the 2-nitrobenzoate degradation pathway of Pseudomonas fluorescens strain KU-7. Appl. Environ. Microbiol. 69: 1564-1572.

23) Obata, H., M. Uebayashi and T. Kaneda. 1988. Purification and properties of 4-hydroxycyclohexanecarboxylate dehydrogenase from Corynebacterium cyclohexanicum. Eur. J. Biochem. 173: 451-458.

24) Quinn, J.A., D.B. McKay and B. Entsch. 2001. Analysis of the pobA and pobR genes controlling expression of $p$-hydroxybenzoate hydroxylase in Azotobacter chroococcum. Gene 264: 77- 
85.

25) Rho, E.M. and W.C. Evans. 1975. The aerobic metabolism of cyclohexanecarboxylic acid by Acinetobacter anitratum. Biochem. J. 148: $11-15$.

26) Sambrook, J., E.F. Fritsch and T. Maniatis. 1989. Molecular cloning: a laboratory manual, 2nd ed. Cold Spring Harbor Laboratory Press, Cold Spring Haber, New York.

27) Schäfer, A., A. Tauch, W. Jäger, J. Kalinowski, G. Thierbach and A. Pühler. 1994. Small mobilizable multi-purpose cloning vectors derived from the Escherichia coli plasmids pK18 and pK19: selection of defined deletions in the chromosome of Corynebacterium glutamicum. Gene 145: 69-73.

28) Schreuder, H.A., J.M. van der Laan, W.G.J. Hol and J. Drenth. 1991. The structure of $p$-hydroxybenzoate hydroxylase, p. 31-64. In E. Müller (ed.), Chemistry and biochemistry of flavoenzymes. CRC Press, Boca Raton FL.

29) Seibold, B., M. Matthes, M.H. Eppink, F. Lingens, W.J. Van Berkel and R. Muller. 1996. 4-Hydroxybenzoate hydroxylase from Pseudomonas sp. CBS3. Purification, characterization, gene cloning, sequence analysis and assignment of structural features determining the coenzyme specificity. Eur. J. Biochem. 239: 469478.

30) Shuman, B. and T.A. Dix. 1993. Cloning, nucleotide sequence, and expression of a $p$-hydroxybenzoate hydroxylase isozyme gene from Pseudomonas fluorescens. J. Biol. Chem. 268: 17057 17062.

31) Smith, S.P., K.R. Barber, S., D. Dunn and G.S. Shaw. 1996.
Structural influence of cation binding to recombinant human brain S100b: evidence for calcium-induced exposure of a hydrophobic surface. Biochem. 35: 8805-8814.

32) Sunnarborg, A., D. Klumpp, T. Chung and D.C. LaPorte. 1990. Regulation of the glyoxylate bypass operon: cloning and characterization of iclR. J. Bacteriol. 172: 2642-2649.

33) Tokuyama, T. and T. Kaneda. 1973. Corynebacterium cyclohexanicum n. sp.: a cyclohexanecarboxylic acid utilizing bacterium. Can. J. Microbiol. 19: 937-942.

34) Trudgill, P.W. 1984. Microbial degradation of the alicyclic ring. In Microbial degradation of organic compounds, ed. Gibson, D.T., Dekker, New York, pp. 131-180.

35) van Berkel, W.J.H. and E. Müller. 1991. Flavin-dependent monooxygenases with special reference to $p$-hydroxybenzoate hydroxylase, p. 1-29. In E. Müller (ed.), Chemistry and biochemistry of flavoenzymes. CRC Press, Boca Raton FL.

36) Williams, R.J. and W.C. Evans. 1975. The metabolism of benzoate by Moraxella species through anaerobic nitrate respiration. Evidence for a reductive pathway. Biochem J. 148: 1-10.

37) Wong, C.M., M.J. Dilworth and A.R. Glenn. 1994. Cloning and sequencing show that 4-hydroxybenzoate hydroxylase (PobA) is required for uptake of 4-hydroxybenzoate in Rhizobium leguminosarum. Microbiol. 140: 2775-2786.

38) Yanisch-Perron, C., J. Vieira, and J. Messing. 1985. Improved M13 phage cloning vectors and host strain: nucleotide sequences of the M13mp18 and pUC19 vectors. Gene 33: 103-119. 